\title{
Estudos sobre Trabalho Global: A necessidade de uma perspetiva emancipatória
}

Études sur le travail global: La nécessité d’une perspective émancipatrice

An Emancipatory Global Labour Studies is Necessary!

\section{Peter Waterman}

Tradutor. João Paulo Galvão

\section{(2) OpenEdition}

\section{Journals}

Edição electrónica

URL: http://journals.openedition.org/rccs/4896

DOI: $10.4000 /$ rccs. 4896

ISSN: 2182-7435

Editora

Centro de Estudos Sociais da Universidade de Coimbra

\section{Edição impressa}

Data de publição: 1 Junho 2012

Paginação: 3-22

ISSN: 0254-1106

\section{Refêrencia eletrónica}

Peter Waterman, «Estudos sobre Trabalho Global: A necessidade de uma perspetiva emancipatória », Revista Crítica de Ciências Sociais [Online], 97 | 2012, colocado online no dia 19 abril 2013, criado a 20 abril 2019. URL : http://journals.openedition.org/rccs/4896 ; DOI : 10.4000/rccs.4896

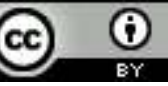




\section{PETER WATERMAN}

\section{Estudos sobre Trabalho Global: A necessidade de uma perspetiva emancipatória*}

O presente artigo faz uma avaliação crítica dos chamados "Novos Estudos sobre Trabalho Global" com base nos seus parâmetros socioliberais, concentrando-se em espaços, locais ou aspetos supranacionais ou globais. Advoga a necessidade de uma perspetiva emancipatória nos "Estudos sobre Trabalho Global", apontando para algumas das fontes teóricas em que se pode basear.

Palavras-chave: emancipação; globalização; sindicalismo; trabalho; trabalhadores.

\section{Prólogo}

Uma estranha loucura apossou-se das classes operárias das nações onde reina a civilização capitalista. Esta loucura arrasta consigo as misérias individuais e sociais que há dois séculos torturam a triste humanidade. Esta loucura é o amor ao trabalho, a paixão mortificante pelo trabalho, levada até ao esgotamento das forças vitais do indivíduo e da sua progenitura. Em vez de reagir contra esta aberração mental, os padres, os economistas, os moralistas santificaram o trabalho. Homens cegos e limitados, quiseram ser mais sábios do que o seu Deus; homens fracos e desprezíveis, quiseram reabilitar aquilo que o seu

Deus amaldiçoara. Eu, que não me confesso cristão, economista e moralista, contesto os seus juízos perante o do seu Deus; contesto as prédicas da sua moral religiosa, económica, livre-pensadora, perante as atrozes consequências do trabalho na sociedade capitalista.

Paul Lafargue (1883)

\footnotetext{
* Trata-se de uma versão muito abreviada de um artigo publicado recentemente em inglês (Waterman, 2012). O original inclui uma extensa bibliografia. Os meus agradecimentos aos avaliadores da RCCS pelos comentários à presente versão, mesmo nos casos em que não consegui concretizar todas as suas justificadas sugestões.
} 
No longo prazo [...] o desenvolvimento da classe trabalhadora mundial terá de proporcionar o contexto para a análise do internacionalismo sindical.

MARCEL VAN DER LiNDEN (2008: 261, nota 6)

Chegou o momento das fornalhas e só deveríamos ver luz. José Martí (carta a José Dolores Poyo, 5 de dezembro de 1891)

\section{Introdução}

Há uma nova onda de aceitação daquilo que começa a autointitular-se os "Novos Estudos sobre Trabalho Global", que vê trabalho, trabalhadores e sindicatos à luz da globalização e, em segunda instância, a um nível local, nacional, regional e global. Deve distinguir-se dos antigos "Estudos Internacionais do Trabalho", que tendiam para a análise comparativa a nível nacional e não global. Pode considerar-se, pelo menos em parte, que esta nova onda acompanha o novo movimento pela solidariedade e justiça global e o conjunto de obras que inspirou. Mas será que os Novos Estudos sobre Trabalho Global (NETG) também se fundamentam e encontram motivação nos novos movimentos sociais populares e radicais democráticos, nos seus novos princípios de articulação ou na sua nova teorização?

Os NETG não seriam novos se não refletissem sobre a crise que o trabalho e os trabalhadores enfrentam atualmente a nível global, bem como sobre a crise do movimento sindical inter/nacional. Têm, por isso, também relevância implícita ou explícita para o sindicalismo inter/nacional. Mas não será que também atiçam as faíscas laborais lançadas pela fornalha da globalização capitalista e do paleo-liberalismo que consome o planeta?

O propósito do presente artigo é, por um lado, avaliar os NETG com base nos seus parâmetros socioliberais, concentrando-se em espaços, locais ou aspetos supranacionais ou globais e, por outro, defender a necessidade de uma perspetiva emancipatória nos Estudos sobre Trabalho Global, apontando para algumas das fontes teóricas em que se pode basear.

\section{Os Novos Estudos sobre Trabalho Global}

Associo os NETG a um determinado livro e uma revista e tenciono utilizá-los aqui como representativos de um diálogo e de um conjunto de obras em crescimento. O livro intitula-se Grounding Globalisation: Labour in the Age of Insecurity, e a revista Global Labour Journal. Verifica-se uma sobreposição dos autores do livro (Webster, Lambert e Bezuidenhout, 2008) e dos diretores da revista, como aliás também existe uma certa sobreposição 
entre estes e a rede de sindicatos Southern Initiative on Globalisation and Trade Union Rights (SIGTUR). Os NETG estão igualmente associados (pelo menos inicialmente?) à Comissão de Investigação sobre Movimentos Laborais (Research Committee on Labor Movements - RC 44), da Associação Internacional de Sociologia, e à Global Labour University, sedeada no Norte, mas primordialmente orientada para o Sul. Há outras ligações - pessoais, profissionais, institucionais e ideológicas - entre os NETG e as tradicionais organizações sindicais inter/nacionais, por um lado, e a Organização Internacional do Trabalho (OIT), por outro. O livro e a revista referidos mostram ser, assim, um relevante objeto de crítica. Por último, os NETG têm um alcance, ou uma força de atração, muito maior no campo mais vasto dos estudos sobre trabalho global e transnacional, constituindo, por isso, mais um complexo ou uma rede cujas características o presente estudo procurará especificar.

\section{O livro}

A obra de Webster, Lambert e Bezuidenhout (2008) (doravante designada apenas por Grounding) é um trabalho original e ambicioso, que deveria suscitar a discussão e encorajar outros estudos de académicos especialistas em trabalho e ativistas investigadores nos próximos anos (ver recensão integral em Waterman, 2011). Grounding centra-se nas atribulações e lutas de operários fabris da indústria de "equipamentos brancos" (frigoríficos, máquinas de lavar, etc.) na Austrália, na Coreia do Sul e na África do Sul. O livro pode ser considerado um grande contributo (pelo menos em inglês) do Sul Global para os crescentes esforços que a esquerda tem levado a cabo para reconceptualizar e reinventar o movimento operário em todo o mundo na era da globalização.

Grounding baseia-se numa reavaliação crítica da teoria de Karl Polanyi, historiador social e sociólogo de esquerda do século Xx, e do seu trabalho amplamente citado e promovido (e.g. Munck, 2002, 2009, 2010) sobre "a grande transformação" provocada pela primeira revolução industrial, o "movimento duplo" que levou a economia capitalista a dominar a sociedade e o modo como este facto causou um movimento para "re-incrustrar" (re-embed) a economia na sociedade. No entanto, Grounding recruta outros teóricos para complementar ou corrigir Polanyi, nomeadamente Sidney Tarrow (2005), sobre os movimentos sociais transnacionais, e Michael Burawoy, sobre movimentos antiglobalização (Burawoy et al., 2000) e a relação de académicos socialmente envolvidos com as pessoas e os movimentos que estudam (2005) (de facto, o título de Webster, Lambert e Bezuidenhout é uma homenagem a Burawoy). Os autores também recorrem a geógrafos sociais radicais, como é o caso de David Harvey, 
com argumentos relativos às operações espaciais do capital e à necessidade de contraestratégias que tenham em conta múltiplos espaços e níveis.

Apesar de não sintetizarem as suas fontes teóricas, muito menos retirarem delas um conjunto de propostas iniciais, os autores utilizam-nas ao longo do trabalho com elegância e eficácia. Curiosamente, Grounding não conceptualiza, na sua introdução teórica, duas noções conexas dos velhos Novos Estudos Internacionais do Trabalho, apesar de surgirem repetidamente em todo o livro: "sindicalismo de movimento social" e "novo internacionalismo operário" (embora este último, como iremos ver, seja definido pelo menos no capítulo 9). Contudo, estes dois conceitos parecem realmente sustentar, ou pelo menos inspirar, o trabalho dos autores. Mais restritiva, porém, é a incapacidade de lidarem com a computorização/informatização enquanto característica fundamental da globalização capitalista e um terreno crucial da luta operária e de outros movimentos sociais. A informatização cria e depende de um outro espaço - o ciberespaço - que os movimentos sociais emancipatórios não podem correr o risco de ignorar. As implicações deste vazio nas peregrinações teóricas de Grounding tornam-se evidentes no capítulo sobre o novo internacionalismo operário.

Este capítulo de Grounding (cap. 9) depende de uma oposição esquemática entre o velho e o novo internacionalismo operário (ou melhor, sindical), cujas características são as seguintes:

\begin{tabular}{ll}
\hline \multicolumn{1}{c}{ Velho internacionalismo operário } & \multicolumn{1}{c}{ Novo internacionalismo operário } \\
\hline Burocratas de carreira & Geração política de ativistas empenhados \\
Hierarquia e burocracia generalizada & Formação em rede \\
Centralização & Descentralização \\
Debate restrito & Debate aberto \\
Orientação diplomática & Orientação para mobilização e campanha \\
Foco exclusivo no local de trabalho & Coligação com novos movimentos \\
e nos sindicatos & sociais e ONGs \\
Predominantemente trabalhadores & Predominantemente trabalhadores \\
estabelecidos, do Norte, do sexo & precários, sul-africanos, \\
masculino, brancos & asiáticos e latinos \\
\hline
\end{tabular}

Embora este esquema de oposição maniqueísta seja uma estratégia comum em termos retóricos (do tipo que eu próprio poderei aplicar), e embora o que aqui nos é apresentado ponha fortemente em causa o velho 
internacionalismo sindical, a caracterização do novo internacionalismo não deixa também de levantar questões. Onde é que está, por exemplo, a alternativa, a oposição ou a superação da "dominação masculina"? Não está na tabela, nem tão pouco no índice do livro, assim como lá não estão "mulheres" ou "feminismo". De facto, não há nesta tabela nenhuma "novidade" em termos de teorias, ideologias ou discursos. Este tipo de apresentações esquemáticas do internacionalismo carece, a meu ver, de ser complementado com elementos mais abrangentes e profundos como os seguintes (Waterman, 1998: 57-63, 235-238):

- a distinção dos diferentes suportes ativos do internacionalismo (organização sindical? movimento operário mais alargado? novos movimentos sociais globais em termos mais gerais? ativistas do movimento operário ou investigadores especialistas em trabalho?);

- os eixos, direcionalidade, alcance e profundidade das campanhas ou ações de solidariedade internacional;

- os possiveis embora problemáticos tipos de solidariedade no âmbito do velho ou do novo internacionalismo (identidade? substituição? complementaridade? reciprocidade? afinidade? restituição?);

- o significado da ação de solidariedade para os trabalhadores nela envolvidos, seja na origem ou fim (ou em qualquer ponto da rede).

Também não estou convencido de que um novo internacionalismo sindical seja ou venha a ser principalmente conduzido pelos trabalhadores do Sul (Waterman, 1998: cap. 5). De facto, pode considerar-se que, para o desenvolvimento de qualquer novo internacionalismo sindical ou operário, é necessário que haja uma dialética e um diálogo global entre

- todas as áreas do mundo - incluindo o aqui esquecido bloco (ex-)comunista e a enorme e nova comuno-capitalista Oficina do Mundo, a China (dificilmente encaixável em qualquer Norte ou Sul homogéneo);

- todos os movimentos de trabalhadores radicais-democratas;

- todos os tipos de movimentos sociais radicalmente democratas;

- movimentos/organizações laborais e académicos socialmente comprometidos.

Os casos do "novo internacionalismo" que este capítulo de Grounding apresenta são todos retirados do Sul geográfico, embora a Austrália faça obviamente parte do Norte socioeconómico e a Coreia do Sul pertença ao Norte geográfico (Seul tem quase a latitude de Lisboa). Mesmo a África do Sul, a mais "socialmente a sul" das três, é um elemento algo atípico do 
Sul global (embora definir um estado/sociedade "tipicamente" do Sul seja hoje problemático). Assim, qualquer oposição maniqueísta, ou mesmo uma simples oposição binária entre Norte e Sul, fica aqui fatalmente fragilizada ou colocada numa situação muito problemática.

O principal exemplo do novo internacionalismo sindical é a Southern Initiative on Globalisation and Trade Union Rights (SIGTUR). Não é por acaso que esta rede liga os principais sindicatos dos três países em estudo neste livro, nem que Rob Lambert, um dos autores de Grounding, é um dos fundadores e um dos principais elementos desta rede, e nem que ele e Eddie Webster são os seus principais promotores académicos. Temos assim que nos perguntar se a excessiva identificação autoral não exagera seriamente a sua importância.

A SIGTUR não tem lugar no Fórum Social Mundial (FSM): ao contrário da Confederação Sindical Coreana (KCTU) e da Confederação Sindical Sul-Africana (COSATU), só esteve presente num FSM. E ao fim de quase duas décadas de existência, a sua presença na Internet é fraca e não dialógica. No entanto, uma presença dialógica na Internet é hoje seguramente um importante requisito de qualquer novo internacionalismo operário. Os autores também não nos oferecem, na apresentação da SIGTUR, aqui ou noutro lado qualquer, uma discussão séria da relação "Norte/Sul" entre os três países que consideram colocar "o desafio fundamental a um Novo Internacionalismo Operário" (209). No entanto, a Austrália, onde a SIGTUR está sedeada, é claramente um lobo do norte numa pele de cordeiro do sul. Até à data, a SIGTUR tem estado encurralada numa contradição ignorada ou não reconhecida - ou, pelo menos, numa tensão fundamental - na tentativa de construir um novo internacionalismo do movimento operário em rede com base nas relações de liderança entre organizações sindicais que reproduzem a base estatal-nacional do velho internacionalismo operário.

Grounding é, por isso, um trabalho ainda encarcerado nos estádios iniciais do capitalismo e nos discursos incrementalistas da esquerda ocidental eurocêntrica, e as estratégias que propõe reproduzem a tradição social-democrata do século XX. Digo "século XX" porque houve uma tradição emancipatória no século XIX e está em curso uma tradição socialista ou social-democrata do século XXI - que se abre à natureza radicalmente transformada do capitalismo global e aos mais recentes movimentos sociais globais que o contestam. ${ }^{1}$ Surpreendente é também o facto de os nossos coautores estarem inteiramente dependentes das teorias e dos teorizadores do Norte, apesar do seu veemente apoio ao Sul.

\footnotetext{
${ }^{1}$ Ver, por exemplo, Bieler, Lindberg e Pillay (2008); Bieler e Lindberg (2011); os blogues New Unionism (http://newunionism.wordpress.com) e UnionBook (http://www.unionbook.org) e o website pluralista e multilingue Global Labour Institute (http://www.global-labour.org).
} 
O máximo a que Grounding pode aspirar é a que, nos seus três casos algo problemáticos do Sul, os sindicatos e os partidos políticos de esquerda venham a suscitar reformas radicais nos (presumivelmente arrependidos) regimes nacional-capitalistas. Em 2012, não houve sinais de tais movimentos e arrependimentos. Mesmo os regimes de esquerda da América Latina, em que os movimentos sociais e operários depositaram tanta esperança nos últimos 5 a 10 anos, estão a ser alvo de críticas e colocados em causa (e.g. Dietrich, 2011). A utopia que os autores promovem (vide cap. 10) não pode deixar de ser vista como uma coisa do passado: a Suécia da década de 1970? À escala mundial? E isto apesar do argumento seguramente razoável de que é a identificação sindical com esta utopia sueca que continua a desarmar, em primeiro lugar, os sindicatos do Norte perante o novo capitalismo, mas também muitos, se não mesmo a maioria, dos sindicatos do Sul, para os quais esta estiolada (senão mesmo já moribunda) Nortutopia se transformou na única que são capazes de imaginar. Consideremos aqui o apoio quase literalmente universal dado pelos sindicatos ao projeto Trabalho Decente ${ }^{2}$ da eurocentrada Organização Internacional do Trabalho (cf. Waterman, 2005).

\section{A polémica}

A publicação de Grounding levou a uma polémica no novo Global Labour Journal, que infelizmente não apontou para uma forma de superar as deficiências dos NETG. Infelizmente também, ficou-se pelo modo de ataque/defesa (Global Issues, vol. 1(3) 2010). Apesar do evidente apreço que Grounding revela pelo trabalho de Michael Burawoy, foi este autor que deu início à polémica num trabalho intitulado "From Polanyi to Pollyanna" (2010a). ${ }^{3}$ Embora a sua crítica a Polanyi e ao Novo Polanyismo seja certamente relevante, o ataque quase inqualificável a Grounding não sugere qualquer alternativa ao movimento operário, ${ }^{4}$ rejeitando não apenas a posição dos autores de Grounding, mas também os Estudos sobre Trabalho Global em geral,

\footnotetext{
${ }^{2}$ Sobre o apoio dos sindicatos do Sul à campanha Trabalho Decente, vide o website da CUT-Brazil, a principal filial latino-americana da SIGTUR (http://www.cut.org.br/cut-em-acao/40/trabalho-decente-na-estrategia-da-cut).

3 Pollyanna é "alguém cujo otimismo é excessivo a ponto de ser ingénuo ou que se recusa a aceitar os factos de uma situação infeliz" (http://en.wikipedia.org/wiki/Pollyanna).

${ }^{4}$ Burawoy regressou com uma réplica (2010b) num tom bastante mais amistoso, mas sem demonstrar qualquer atitude otimista que pudesse temperar o seu pessimismo intelectual. O seu problema poderá residir na distinção ou oposição que estabelece entre trabalho académico e envolvimento político. Burawoy parece considerar que o (seu?) trabalho académico está comprometido com a verdade ou com a ciência, ao passo que o envolvimento político (dos outros?) implica uma idealização das realidades e das possibilidades. Embora reconheça a tensão entre estes dois tipos de prática, não encontrei - e continuo a não encontrar - estudos académicos sobre trabalho que sejam assim tão científicos, nem trabalho político que exija necessariamente uma idealização.
} 
que considera excessiva, irremediável e falsamente otimistas. Burawoy parece ver hoje a necessidade de um movimento baseado não tanto em classes como em espécies, mas apesar disso conclui aqui que:

Pode ser necessária uma espécie de contramovimento global para a sobrevivência humana, mas não existe uma necessidade histórica que o leve a aparecer [...] Um contramovimento que evite o desastre ecológico só pode ser imposto por um regime autoritário $[\ldots]$ Poderá haver pequenos contramovimentos $[\ldots]$ mas os cuidados paliativos poderão impedir todo e qualquer envolvimento coletivo para conter as tendências predatórias do capitalismo. (Burawoy 2010a:311)

Dada a evidência de um crescente protesto global contra a guerra, o imperialismo, as alterações climáticas, a desflorestação, os organismos e alimentos geneticamente modificados, a discriminação sexual e patriarcal, a publicidade, o extrativismo, eu diria que Burawoy revela um pessimismo fatalista que - como muitos dos seus interlocutores sugerem (Global Issues, 2010) - serve apenas para desencorajar a luta.

Pergunto-me se a combinação nesta polémica de um otimismo reconhecidamente irrealista com um absoluto pessimismo não poderá dever-se: 1) ao facto de ambas as partes tomarem como referência fundamental a teoria crítica e socialmente empenhada de Karl Marx e Karl Polanyi sobre a sociedade capitalista industrial, o descontentamento social e os movimentos emancipatórios; e 2) ao facto de se basearem, talvez demasiado, na distinção ou oposição entre a teoria da exploração do primeiro e a teoria da mercadorização do segundo.

É minha convicção que, independentemente das grandes perspetivas ou inspirações teóricas, metodológicas, analíticas ou estratégicas que possam proporcionar aos estudos sobre trabalho global de hoje, os Dois Karls - separadamente ou em conjunto - não oferecem uma base suficientemente teórica para um movimento emancipatório nas condições radicalmente diferentes do capitalismo atual. Claro que o Karl 1 e o Karl 2 também não seriam adequados ao século XIX e ao século XX. Nem as estratégias de classe de Marx nem as estratégias de Sociedade+Estado derivadas (pelo menos implicitamente) de Polanyi conseguiram ter mais do que um êxito temporário, parcial e tragicamente reversível. Refiro-me aqui, obviamente, ao colapso do projeto comunista e do projeto socialista para o terceiro mundo, assentes no marxismo, e à gradual destruição/desintegração dos Estados-Providência capitalistas inspirados (mais uma vez implicitamente) em Polanyi.

O facto de a Global Labour Journal ter acolhido esta polémica é de louvar. Mas tanto a polémica como vários outros contributos e recensões 
críticas publicadas na revista levam-me a pensar que são necessários "Outros Estudos sobre Trabalho Global".

\section{Novas perspetivas}

"Emancipatório" é, obviamente, um termo antigo, frequentemente usado para referir a inclusão dos oprimidos, explorados, excluídos e discriminados numa sociedade ou numa comunidade organizada, muitas vezes apenas em termos de direitos políticos. Contudo, na tradição marxista, acabou por significar emancipação do capitalismo, como na designação do primeiro partido marxista russo, o Grupo Emancipação do Trabalho. ${ }^{5}$ No que se refere à classe trabalhadora, tendia a reduzir a emancipação principal e quase exclusivamente à eliminação da exploração capitalista sob a forma de trabalho assalariado. Prefiro conceber a emancipação como o contraponto da alienação em todas as suas formas. É assim que Erik Olin Wright parece entendê-la:

A ciência social emancipatória, no seu sentido mais amplo, procura gerar conhecimento relevante para o projeto coletivo de desafiar a opressão humana e de criar condições para as pessoas poderem ter uma vida próspera. Chamar-lhe ciência social em vez de filosofia ou crítica social é reconhecer a importância para esta tarefa do conhecimento científico sistemático sobre o funcionamento do mundo. Chamar-lhe emancipatória é identificar o seu propósito moral central - a eliminação da opressão e a criação de condições para a prosperidade humana. E chamar-lhe social implica a crença de que a emancipação depende da transformação do mundo social, não apenas do eu interior. Para cumprir a sua missão, qualquer ciência social emancipatória fica perante três tarefas básicas: primeiro, fazer uma crítica e um diagnóstico sistemático do mundo tal como existe; segundo, imaginar alternativas viáveis; e terceiro, compreender os obstáculos, as possibilidades e os dilemas da transformação. Em diferentes momentos históricos, uma delas pode impor-se com mais urgência do que as outras, mas todas são necessárias para uma teoria emancipatória abrangente. (2006: 94)

E aqui aparecem as esferas cruciais do esforço emancipatório sugerido nos vários volumes da coleção dirigida por Boaventura de Sousa Santos

\footnotetext{
${ }^{5}$ Ver Marxists Internet Archive (http://www.marxists.org/glossary/orgs/e/m.htm).

${ }^{6}$ Para uma alternativa e posterior fonte para o argumento de Olin Wright, ver "The Tasks of Emancipatory Social Science”, disponível em http://www.ssc.wisc.edu/ wright/ERU_files/ERU-CHAPTER-2-final.pdf.
} 
(2007-2010), Reinventing Social Emancipation: Toward New Manifestos. ${ }^{7}$ Este projeto aponta implicitamente para a necessária articulação da democracia participativa, dos sistemas de produção alternativos, do multiculturalismo, da justiça e da cidadania, da biodiversidade, dos conhecimentos rivais, dos direitos de propriedade intelectual e até mesmo de... um novo internacionalismo operário (Waterman, 2006: 446). Qualquer pessoa pode (e deve) aumentar esta lista. Eu próprio poderia acrescentar ciberespaço libertador. E embora ache que a última área de Boaventura de Sousa Santos devesse ser Novo(s) Internacionalismo(s) - e embora possamos continuar à espera de um volume de ou sobre Novos Manifestos - acho que podemos retirar uma orientação geral dos dois autores citados. Podíamos, assim, começar a entender a emancipação social global como o projeto de desenvolvimento de uma conceção pós-capitalista, pós-liberal (e pós-estado-socialista) de democracia, produção, direitos e conhecimentos, de um ciberespaço libertador e de uma nova solidariedade global - no âmbito da qual uma nova solidariedade operária global teria um papel a desempenhar. ${ }^{8}$

Que significado mais específico poderia a emancipação social ter hoje para os trabalhadores? De facto, o clássico movimento operário (britânico) teve duas grandes divisas emancipatórias relacionadas com o trabalho. Uma delas era "A Fair Day's Wage for a Fair Day's Work". ' No início, esta noção era seguramente uma noção cristã, sendo mais tarde integrada, juntamente com outros ditos religiosos convenientes, no liberalismo social. Como divisa emancipatória, exprimia claramente a ideia da conquista de direitos numa sociedade capitalista e numa organização política liberal. É aqui que residem as raízes políticas (ou espirituais?) do Trabalho Decente. A outra divisa histórica era "The Abolition of Wage-Slavery", ${ }^{10} \mathrm{o}$ alvo fundamental dos Trabalhadores Industriais do Mundo (o conhecido IWW, ou Wobblies), anarco-sindicalistas (e internacionalistas): ${ }^{11}$

\footnotetext{
7 Publicada inicialmente em português com o título Reinventar a Emancipação Social: Para Novos Manifestos (http://www.ces.uc.pt/publicacoes/res/). [N. T.]

${ }^{8}$ Só na última reformulação do presente trabalho é que tomei conhecimento do ensaio de Ernesto Laclau (1996) "Beyond Emancipation", que merece obviamente mais atenção do a que aqui lhe posso dedicar. $\mathrm{O}$ autor parece sugerir que este conceito está dependente das condições de não liberdade que o próprio conceito nega, e que não tem capacidade nem conteúdo construtivo (criativo?). Porém, a menos que o autor ou alguém mais ofereça uma ou mais alternativas construtivas, acho que consigo lidar com a negação que a emancipação faz das várias - e cada vez mais perigosas não-liberdades com as quais somos confrontados.

9 "Um salário diário justo para um dia de trabalho justo". [N. T.]

10 "A abolição da escravatura salarial". [N. T.]

${ }^{11}$ Extraído de Working Men Unite!, de E. S. Nelson, incluído no livro de canções dos Wobblies intitulado Little Red Songbook. Disponível em http://www.angelfire.com/nj3/RonMBaseman/ songbk.htm.
} 
Conditions they are bad,

And some of you are sad;

You cannot see your enemy,

The class that lives in luxury,

You workingmen are poor,

Will be for evermore,

As long as you permit the few

To guide your destiny.

CHORUS

Shall we still be slaves and work for wages?

It is outrageous - has been for ages;

This earth by right belongs to toilers,

And not to spoilers of liberty. ${ }^{12}$

Com um ar mais contemporâneo, a ideia reaparece em Andre Gorz (1999), que faz apelo a "The Liberation of Time from Work" ${ }^{13}$ Na medida em que Gorz considera que, no Ocidente, chegámos ao fim da "sociedade assente no trabalho", esta divisa poderá ser considerada eurocêntrica, mas deve ser entendida como a expressão de uma luta global contra o trabalho capitalista forçado e a falta de trabalho. ${ }^{14} \mathrm{~A}$ ideia manifesta-se no Sul, particularmente na América Latina, nas tentativas de conceptualizar e pôr em prática uma "economia solidária" - uma questão importante em sucessivos encontros do Fórum Social Mundial. ${ }^{15}$ A ligação desta ideia à antiga e atual reivindicação da libertação dos bens comuns (socializando um mundo cada vez mais privatizado/mercantilizado ${ }^{16}$ permitiria que se desenvolvesse uma inter-relação com o movimento pela justiça e solidariedade global (com os seus movimentos ecológico, de cidadania, das mulheres, pela habitação e rural). No mínimo, deve dar-se à divisa de Gorz o mérito de desnaturalizar o "trabalho", enquanto muitos especialistas e ativistas de

\footnotetext{
${ }^{12}$ Condições miseráveis, || Rostos deploráveis; || Não vês o inimigo, || A classe no luxo do abrigo, || Tu que trabalhas és pobre, || Será sempre assim, || Enquanto deixares que poucos || Guiem o teu destino. || CORO || Continuamos escravos a trabalhar para viver? || É ultrajante - há anos que tem de ser; || A terra por direito é dos trabalhadores, || E não dos que dão cabo da liberdade, os senhores. [N. T.]

13 "Libertar o Tempo do Trabalho". [N. T.]

${ }^{14} \mathrm{O}$ facto de o capitalismo produzir simultaneamente a fome e a obesidade prova que isto não é um paradoxo.

15 Embora este seja também um conceito muito questionado e em relação ao qual vários governos assumem diferentes posições (ver http://www.globenet3.org/Articles/Article_Argentina_Solidarity. shtml). Curiosamente, o Fórum Social dos Estados Unidos (2010) deu origem a uma rede de economia solidária (http://www.solidarityeconomy.net/about-solidarityeconomynet).

${ }^{16}$ Cf. Waterman, 2003 e The Commoner (http://www.commoner.org.uk).
} 
esquerda o tomam simplesmente como um dado adquirido. De qualquer forma, há outros autores que continuam a lutar contra a escravatura do trabalho assalariado (e.g., Carlín, 2010; Carlsson, 2008; Holloway, 2010; Porcaro, 2008; Sinclair, 2001). Note-se que a maior parte dos autores que contribuem para o NETG, senão mesmo todos, não questionam, nem tão pouco põem em causa, a noção de "trabalho" como alienação do trabalho humano pelo capital/Estado. Mostram-se, sim, preocupados em melhorar as condições em que tal acontece. Passarei então a especificar algumas das mais recentes contestações ao "trabalho", referindo dois ou três dos autores que mencionei.

Baseando-se na economia política marxista clássica, John Holloway distingue "trabalho" (labour) e "ação" (doing):

Há dois tipos de atividade: um que é imposto externamente e que vivenciamos diretamente como algo de desagradável ou como parte de um sistema que rejeitamos, e outro que incentiva a autodeterminação. Precisamos efetivamente de dois termos para estes dois tipos de atividade. Seguiremos a sugestão de Engels numa nota de rodapé do Capital (Marx, 1965 [1867]: 47) que se refere ao primeiro tipo de atividade como trabalho e ao segundo simplesmente como fazer/ação. As autonomias podem assim ser vistas como revoltas do fazer contra o trabalho. (Holloway 2010: 909)

Mimmo Porcaro, ao refletir sobre a fragmentação atual do que outrora foi (considerada) uma classe operária homogénea, baseia-se no historiador marxista E. P. Thompson para realçar o contexto não-industrial no qual se constituiu a classe operária inglesa:

Se os resultados de uma investigação [...] confirmam que hoje, tal como no passado, os germes da consciência coletiva se desenvolvem primordialmente fora do emprego, confirmar-se-ia que (especialmente hoje em dia) o principal espaço para a formação de uma potencial consciência de classe não é a produção, mas a própria vida em todas as suas formas. Será que isto implica um enfraquecimento do discurso socialista? Permitam-me dizer que só se consegue criar um movimento coletivo de trabalhadores (e outros) orientado para a transformação social se e quando a "consciência" toma forma como resultado de "toda a experiência de vida", porque ideias fortes capazes de influenciar verdadeiramente a política, ideias "públicas" ao dispor de toda e qualquer pessoa, independentemente da sua classe e família, ideias organizadas em causas [...] só conseguem surgir do conjunto da experiência de vida. [...]

Esta [necessária] nova investigação assemelha-se àquilo em que deve tornar-se uma nova política: a interligação de milhares de experiências heterogéneas a partir das 
quais poderá emergir uma entidade coletiva sem precedentes. Esta entidade não vai emergir de abstrações: nem do Trabalho, nem da Vida, nem da Política. O Trabalho, a Vida e a Política são, de alguma forma, "neutros": são campos de batalha que podem ter diferentes resultados, incluindo, respetivamente, o obreirismo, o refúgio no quotidiano ou o oportunismo. Pelo contrário, a nova entidade será construída a partir das escolhas concretas, logo imprevisíveis, de milhões de homens e mulheres que vão querer tomar o partido de um destes campos de batalha para encontrarem uma solução que não reproduza as hierarquias de hoje: uma solução não repetitiva, não concebida antecipadamente, a que melhor se adapte a uma consciência do contexto histórico, capaz de dar um novo nome ao presente e ao futuro. (Porcaro, 2008)

O autor chega mesmo a sugerir que talvez seja a partir das experiências comuns e do descontentamento do consumo mercantilizado e da vida familiar mercantilizada que a consciência e a ação emancipatória podem ser construídas.

Há, contudo, um importante trabalho recente sobre a atual natureza do trabalho e dos trabalhadores que está firmemente ancorado nas condições de uma região e de um país do Sul. Trata-se do livro de Franco Barchiesi (2011), também ele italiano da tradição autonomista, baseado numa pesquisa etnográfica entre trabalhadores sul-africanos, que se concentra menos na questão da sua identidade/diferença relativamente a outros trabalhadores africanos do que em apresentar argumentos e provas para tal. O seu foco incide na relação entre a perceção que os trabalhadores têm do seu próprio trabalho e o seu comportamento enquanto cidadãos. As conclusões a que chega não são as de uma Pollyanna incremental ou insurrecional. Embora, à semelhança dos nossos anteriores autores autonomistas, Barchiesi desvie o foco da nossa atenção do emprego assalariado formal numa grande empresa para a comunidade mais lata de residência e trabalho, no capítulo 6 aborda

a forma como os trabalhadores articulam politicamente o seu desejo de ultrapassar/se libertar de uma vida dura e precária no local de trabalho. Há uns que tentam lidar com a mudança através de uma renovada imaginação ativista que apela, para além das paredes da fábrica, à mobilização da comunidade e à reivindicação de serviços sociais [des]mercantilizados. Mais generalizada, contudo, é a atitude de contínua dependência do CNA [Congresso Nacional Africano] no que respeita a políticas de proteção e criação de emprego. Numa aparente contradição com o pouco apreço que os trabalhadores têm pelos seus próprios empregos, este tipo de reivindicação revela, no quadro daquilo a que chamo uma política emergente de melancolia operária, 
aspirações a uma ordem social idealizada, na qual o trabalho garanta relações de autoridade com base no género, na idade e na nacionalidade. Este tipo de desenvolvimentos suscita a inquietante possibilidade de o discurso emancipatório, ao manter o trabalho no centro da sua conceção de cidadania, poder com facilidade e inadvertidamente alimentar fantasias autoritárias e chauvinistas. (Barchiesi, 2011: 25)

A obra de Barchiesi prova que uma nova abordagem teórica do trabalho não implica necessariamente otimismo sobre a sua função, mas uma mudança do domínio em análise e dos termos do debate.

Ilda Lindell tem desenvolvido uma vasta investigação sobre o setor informal na África do Sul (2009, 2011a, b, c) e sobre formas de organização transnacional (Lindell, 2011a, b), utilizando os conceitos sociogeográficos de espaço e escala (sobre os quais ver também Munck, 2010) e questionando a primazia dada quer ao global quer ao local em estudos sobre trabalho informal. Com base em dois estudos de caso de Moçambique, conclui que, curiosamente, não se pode identificar como sendo "correta" quer a estratégia "de baixo para cima" (bottom-up) quer a "de cima para baixo" (top-down) (promovidas pela Oxfam), com a implicação de que há várias estratégias capazes de influenciar positivamente o autoempoderamento e com impacto político a nível local/nacional/internacional. Na sua introdução ao número temático da revista Labour, Capital and Society sobre a separação entre os setores formal e informal (Lindell, 2011c), a autora considera todos os desafios que a auto-organização coletiva fora do "setor formal" coloca aos tradicionais sindicatos e ao sindicalismo.

Na sua investigação sobre o que eu consideraria iniciativas de trabalho emancipatório, Melisa Serrano e Edlira Xhafa (2011a, b) (bem como os participantes de um projeto de investigação da Global Labour University) concentram-se em "alternativas" ou em suplantar o "cânone capitalista". Também incorporam na sua argumentação a noção de pluralidade, dialética e diálogo que proponho como componente de uma perspetiva emancipatória nos Estudos sobre o Trabalho Global. Fazem uma avaliação crítica da literatura "alternativa", sugerem uma metodologia de investigação, apresentam estudos de caso e defendem que o seu próprio trabalho

visa contribuir para o discurso sobre alternativas ao capitalismo estabelecendo um “diálogo" entre debates teóricos [...] e experiências sociais concretas [...]. Com isto, pretendemos incluir esses debates teóricos na perspetiva de quem está envolvido nas práticas e lutas de modo a desenvolver a sua consciência e as suas capacidades para se tornarem sujeitos da transformação [...]. Por último, ao identificarmos elementos comuns a várias lutas e experiências [...], procuramos ligar essas lutas e 
[...] contribuir para a construção de uma alternativa coerente e inspiradora ao capitalismo. (Serano e Xhafa, 2011a: 20)

A maior parte dos projetos de investigação é relativa a alternativas locais na esfera económica, como é o caso das fábricas geridas por trabalhadores na Argentina e na Índia, das cooperativas informais de trabalhadores e dos projetos de microcrédito em Moçambique, na Índia, no Brasil e nas Filipinas, dos programas democráticos e participativos iniciados ou financiados pelo Estado no Brasil e no Quebeque, e das parcerias para o desenvolvimento económico e comunitário na Austrália. As autoras dão-nos ainda exemplos de outras iniciativas apoiadas por sindicatos e, como já mencionado, pelo Estado. E embora nos acautelem contra a idealização dos projetos bem-sucedidos, também defendem que deve haver o desenvolvimento de uma consciência relativamente àquilo que consideram ultrapassar, potencialmente, a lógica capitalista. Concluem assim que

[a] identificação de aspetos ou elementos comuns nas lutas com um potencial transformador ou emancipatório e a sua ligação a [uma variedade de] discursos teóricos [emancipatórios] contribuem para um processo de associação das lutas das pessoas em todo o mundo, na busca comum de uma alternativa coerente e inspiradora ao capitalismo. (Serrano and Xhafa, 2011a: 32)

Chris Carlsson, dos EUA, pertence a uma tradição americana libertária e utópica de esquerda (cf. Sinclair, 2001), está familiarizado com Marx e os marxismos e os seus principais interesses têm a ver com questões de trabalho e de classe. Contudo, não só abandona os tradicionais terrenos e meios da ação dos movimentos operários, como sugere, em vez disso, que a emancipação da escravatura do trabalho assalariado exige que este seja marginalizado ou que dele se saia (ou seja expulso), criando novas comunidades de produção, distribuição e troca na periferia, ou fora dos parâmetros, do capital e do Estado. Para este autor, o início do capitalismo deu-se com o cercamento dos baldios/terrenos comunitários, e o objetivo do projeto emancipatório é restabelecer os bens comuns de acordo com as atuais circunstâncias. $\mathrm{Na}$ sua opinião, isto não é uma possibilidade futura e nem sequer implica uma revolução apocalíptica. Encontra a sua "Agorutopia” (Carlsson, 2008) nos EUA do presente e oferece-nos múltiplos e variados exemplos disso mesmo, como as atividades dos "programadores piratas, ciclistas proscritos e jardineiros de lotes vazios”, para citar o subtítulo do seu livro. Estes exemplos podem afigurar-se como atividades tipicamente norte-americanas ou até mesmo californianas, dependentes de condições de sobrevivência que 
só aí existem. E, de facto, quase não há referências à Ásia, África e América Latina. Contudo, as atividades individuais ou orientadas para o coletivo que o autor apresenta de forma bastante pormenorizada certamente terão paralelos no precariado maioritário do Sul global. E há ainda lições que se podem aprender internacionalmente sobre a forma como os trabalhadores estão a reagir nos seus países às contradições do capitalismo globalizado, informatizado, em rede e paleo-liberal.

Atendendo às elogiosas recensões críticas feitas à obra no seu todo, ${ }^{17}$ vou concentrar-me naquilo que no livro de Carlsson é simultaneamente a área mais californiana e mais internacional do trabalho alienado e do trabalho autocriado, "The Virtual Spine of the Commons" (cap. 8). Ao contrário dos nossos anteriores autores "emancipatórios", Carlsson dá relevo na sua obra à luta conduzida dentro e à volta da Internet. Considera que, "apesar de a maioria das pessoas não trabalhar em áreas relacionadas com computadores ou com a Internet, a crescente precariedade do emprego fixo na maioria das áreas assemelha-se às relações que emergem no trabalho on-line e afim" (187). Carlsson reconhece as contradições inerentes à produção de software gratuito e outras atividades emancipatórias no ciberespaço - em particular, obviamente, a capacidade do capitalismo da informação para transformar essa produção criativa e cooperativa num negócio rentável. Embora nem sequer idealize os ciberespaços mais aventureiros, como a Wikipédia ou a Indymedia, orientada para movimentos, considera que

o capital reorganizou os sistemas de produção do planeta com linhas de fornecimento em tempo útil [just in time supply], desempregando trabalhadores integrados e sindicalizados a favor de mão-de-obra passageira, imigrante e temporária sempre que possível. As comunidades recém-emergentes on-line, facilitadas por muitas das iniciativas organizativas baseadas na Internet, representam uma outra faceta de uma emergente recomposição da classe trabalhadora. Novos sites e formas de resistência à acumulação do capital começam a tomar forma e a fazer-se sentir nos movimentos contra a globalização e contra a guerra, em campanhas pela imigração tecnologicamente inteligentes no hemisfério norte, demonstrando a notável plasticidade dos incansáveis esforços dos rebeldes digitais sem rosto que se recusam a sucumbir às práticas ou prioridades do negócio/das empresas. (207)

${ }_{17}$ Ver as recensões de Robert Ovetz em The Commoner (2010) e de Ben Dangl em Zmaganize (2008), disponíveis respetivamente em http://www.commoner.org.uk/?p=89 e http://www.zcommunications.org/nowtopia-by-ben-dangl. 


\section{Conclusão: um longo percurso pela literatura}

A "emancipação" é uma aspiração e não uma "linha" ou uma "posição". Não existe apenas uma pluralidade de centelhas, mas também de fornalhas que as lançam para o exterior. Boaventura de Sousa Santos (2004) fala da necessidade de identificar

dois processos que designo como sociologia das ausências e sociologia das emergências. Falo de sociologias, pois o meu propósito é identificar criticamente as condições que destroem a experiência social não-hegemónica e potencialmente contra-hegemónica. Através destas sociologias, a experiência social que resiste à destruição é desocultada, e abre-se o espaço-tempo capaz de identificar e tornar credíveis novas experiências sociais contra-hegemónicas.

Nas palavras do veterano sindical internacional Dan Gallin (apud Hall-Jones, 2011),

Muitos de nós vêm de uma tradição que nos incentiva a pensar que cada um de nós é capaz de providenciar a centelha sozinho se tiver a política correta (que é o resíduo acastanhado que fica no fundo do tacho depois de muitas ruturas terem deixado a água evaporar-se) e se se esforçar o suficiente [...] Cheguei finalmente à conclusão de que isto é um disparate. A centelha que nós queremos não pode vir de nenhum de nós, só pode vir da combinação/interação entre muitos de nós. Por outras palavras, esqueçam o partido de vanguarda, a rede é a vanguarda.

Este é um apaixonado grito de guerra que nos dá que pensar, vindo como vem de alguém que passou a maior parte da sua vida ativa no seio de organizações sindicais internacionais eurocentradas e eurocêntricas. E, correndo o risco de repetição, sugere-me que os estudos sobre trabalho global de teor emancipatório têm de resultar igualmente do tipo de dialética e diálogo aberto, igualitário e radicalmente democrático que o termo "rede" evoca.

Tradução de João Paulo Galvão

Revisão de Teresa Tavares

\section{Referências bibliográficas}

Barchiesi, Franco (2011), Precarious Liberation. Workers, the State, and Contested Social Citizenship in Postapartheid South Africa. Albany, NY: State University of New York Press. 
Bieler, Andreas; Lindberg, Ingemar (orgs.) (2011), Global Restructuring, Labour and the Challenges for Transnational Solidarity. Abingdon: Routledge.

Bieler, Andreas; Lindberg, Ingemar; Pillay, Devan (orgs.) (2008), Labour and the Challenges of Globalisation: What Prospects for Transnational Solidarity? London: Pluto.

Burawoy, Michael et. al. (2000), Global Ethnography: Forces, Connections, and Imaginations in a Postmodern World. Berkeley: California University Press.

Burawoy, Michael (2005), "2004 American Sociological Association Presidential Address: For Public Sociology”, American Sociological Review, 70(1), 4-28.

Burawoy, Michael (2010a), "From Polanyi to Pollyanna: The False Optimism of Global Labor Studies”, Global Labour Journal, 1(2), 301-313. Consultado em http://digitalcommons.mcmaster.ca/globallabour/vol1/iss2/7.

Burawoy, Michael (2010b), “On Uncompromising Pessimism: Response to My Critics”, Global Labour Journal, 2(1), 73-77. Consultado em http://digitalcommons.mcmaster. ca/globallabour/vol2/iss1/8/.

Carlín (Tovar, Carlos) (2010), "Manifesto of the $21^{\text {st }}$ Century”. Consultado em http:// manifestoofthe21stcentury.blogspot.com/.

Carlsson, Chris (2008), Nowtopia: How Pirate Programmers, Outlaw Bicyclists, and Vacant-Lot Gardeners are Inventing the Future Today. Oakland: AK Press.

Dieterich, Heinz (2011), "Fin de la esperanza estatal”. Blogue Outra Política. Consultado em http://outrapolitica.wordpress.com/2011/04/15/fin-de-la-esperanza-estatal/.

Gorz, Andre (1999), “A New Task for the Unions: The Liberation of Time from Work”, in Ronaldo Munck e Peter Waterman (orgs.), Labour Worldwide in the Era of Globalisation: Alternative Union Models in the New World Order Houndmills. Macmillan.

Global Issues (2010), Global Labour Journal, 1(3). Consultado em http://digitalcommons.mcmaster.ca/globallabour/vol1/iss3/.

Hall-Jones, Peter (2011), "End of an Error". Consultado em http://newunionism. wordpress.com/2011/03/22/wftu/.

Holloway, John (2010), Crack Capitalism! London: Pluto Press.

Laclau, Ernesto (1996), "Beyond Emancipation”, in Emancipation(s). London: Verso, 1-19.

Lafargue, Paul (1883), "The Right to be Lazy”. Colocado online em 2000, através de Lafargue Internet Archive (marxists.org). Consultado em http://www.marxists. org/archive/lafargue/1883/lazy/index.htm.

Lindell, Ilda (2009), “'Glocal' Movements: Place Struggles and Transnational Organising by Informal Workers”, Geografiska Annaler: Series B - Human Geography, 91(2), 123-136.

Lindell, Ilda (2011a), "The Contested Spatialities of Transnational Activism: Gendered Gatekeeping and Gender Struggles in an African Association of Informal Workers”, Global Networks, 11(2), 222-241. 
Lindell, Ilda (2011b), "Informal Work and Transnational Organising”, in Andreas Bieler e Ingemar Lindberg (orgs.), Global Restructuring, Labour and the Challenges for Transnational Solidarity. Abingdon: Routledge, 75-86.

Lindell, Ilda (coorg.) (2011c), "Organising Across the Formal-Informal Worker Constituencies", Labour, Capital and Society - Special Issue "Formal/Informal Divide", 44(1), 4-16. Consultado em http://www.lcs-tcs.com/PDFs/44_1/1\%20Lindell.pdf. Munck, Ronaldo (2002), Globalisation and Labour: The New Great Transformation. London: Zed.

Munck, Ronaldo (2009), “Afterword: Beyond the “New” International Labour Studies”, Third World Quarterly, 30(3), 617-25.

Munck, Ronaldo (2010), "Globalisation, Labour and Development: A View from the South", Transformation, 72-73, 205-224.

Porcaro, Mimmo (2008), "Labour and Life: Memorandum for a Future Investigation of (Class?) Consciousness", Transform! European Network for Alternative Thinking and Political Dialogue, 2. Consultado em http://transform-network.net/journal/ issue-022008/news/detail/Journal/labour-and-life-memorandum-for-a-future-investigation-of-class-consciousness.html.

Serrano, Melisa; Xhafa, Edlira (2011a), "Beyond the Capitalist Logic: Theoretical Debates and Social Experiences”, in Melisa Serrano; Edlira Xhafa e Michael Fichter (orgs.), Trade Unions and the Global Crisis: Labour's Visions, Strategies and Responses. Geneva: Internacional Labour Office, 19-34.

Serrano, Melisa; Xhafa, Edlira (2011b), “The Quest for Alternatives Beyond (Neoliberal) Capitalism”, Global Labour University Working Paper, no.14. Geneva: International Labour Office.

Sinclair, Gabe (s.d.), Blogue The Four-Hour Day: A Time Whose Idea has Come. Consultado em http://www.fourhourday.org/.

Santos, Boaventura de Sousa (2004), "The World Social Forum: Toward a Counter-Hegemonic Globalisation (Part I)”. Consultado em http://www.choike.org/documentos/wsf_s318_sousa.pdf.

Santos, Boaventura de Sousa (2007-2010), Reinventing Social Emancipation: Towards New Manifestos (4 vol.). London: Verso.

Tarrow, Sydney (2005), The New Transnational Activism. New York: New York University Press.

van der Linden, Marcel (2008), Workers of the World: Essays Toward a Global Labour History. Leiden: Brill.

Waterman, Peter (1998), Globalisation, Social Movements and the New Internationalisms. London: Continuum.

Waterman, Peter (2003), “All in Common: A New/Old Slogan for International Labour and Labour Internationalism”. Consultado em http://www.commoner.org.uk/waterman06.pdf. 
Waterman, Peter (2005), “From 'Decent Work' to 'The Liberation of Time from Work': Reflections on Work, Emancipation, Utopia and the Global Justice and Solidarity Movement". Consultado em www.struggle.ws/anarkismo/peterwork.pdf.

Waterman, Peter (2006), "Emancipating Labour Internationalism”, in Boaventura de Sousa Santos (org.), Another Production is Possible: Beyond the Capitalist Canon. London: Verso, 446-480. Consultado em http://www.interfacejournal. net/2012/11/interface-volume-4-issue-2-for-the-global-emancipation-of-labour/.

Waterman, Peter (2011), "Review of 'Grounding Globalisation: Labour in the Age of Insecurity”, Review of Radical Political Economy, 43(3), 392-399.

Waterman, Peter (2012), “An Emancipatory Global Labour Studies is Necessary! On Rethinking the Global Labour Movement in the Hour Of Furnaces”, Interface, vol. 4, n. ${ }^{\circ}$ 2. Consultado em http://www.interfacejournal.net/2012/11/interface-volume-4 -issue-2-for-the-global-emancipation-of-labour/.

Webster, Eddie; Lambert, Rob; Bezuidenhout, Andries (2008), Grounding Globalisation: Labour in the Age of Insecurity. Oxford: Wylie-Blackwell.

Wright, Erik Olin (2006), "Compasspoints: Towards a Socialist Alternative”, New Left Review, 41, 93-124. 